
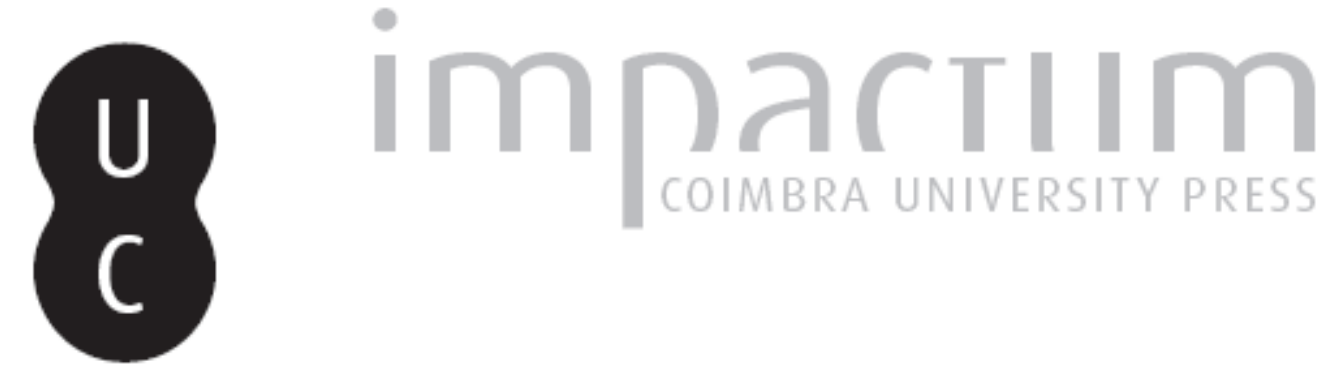

\title{
Foram os Hititas Henoteístas? A palavra Siu no contexto do Hitita do Antigo Reino
}

Autor(es): $\quad$ Freitas, António José Gonçalves de

Publicado por: Centro de História da Universidade de Lisboa

URL persistente:

URI:http://hdl.handle.net/10316.2/23597

DOI:

DOI:http://dx.doi.org/10.14195/0871-9527_21_6

Accessed : $\quad$ 26-Apr-2023 15:26:25

A navegação consulta e descarregamento dos títulos inseridos nas Bibliotecas Digitais UC Digitalis, UC Pombalina e UC Impactum, pressupõem a aceitação plena e sem reservas dos Termos e Condições de Uso destas Bibliotecas Digitais, disponíveis em https://digitalis.uc.pt/pt-pt/termos.

Conforme exposto nos referidos Termos e Condições de Uso, o descarregamento de títulos de acesso restrito requer uma licença válida de autorização devendo o utilizador aceder ao(s) documento(s) a partir de um endereço de IP da instituição detentora da supramencionada licença.

Ao utilizador é apenas permitido o descarregamento para uso pessoal, pelo que o emprego do(s) título(s) descarregado(s) para outro fim, designadamente comercial, carece de autorização do respetivo autor ou editor da obra.

Na medida em que todas as obras da UC Digitalis se encontram protegidas pelo Código do Direito de Autor e Direitos Conexos e demais legislação aplicável, toda a cópia, parcial ou total, deste documento, nos casos em que é legalmente admitida, deverá conter ou fazer-se acompanhar por este aviso.

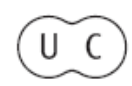



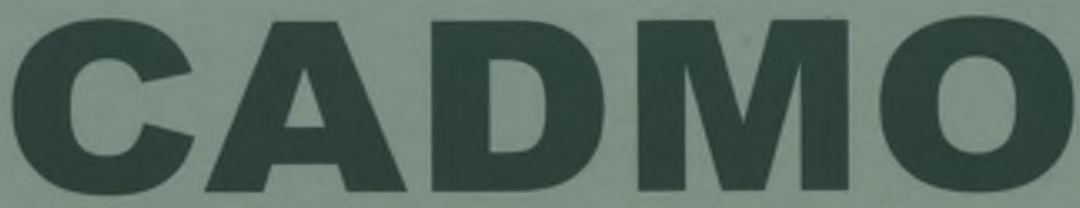

Revista de História Antiga

\author{
Centro de História \\ da Universidade de Lisboa
}

\title{
21
}

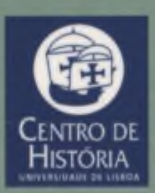

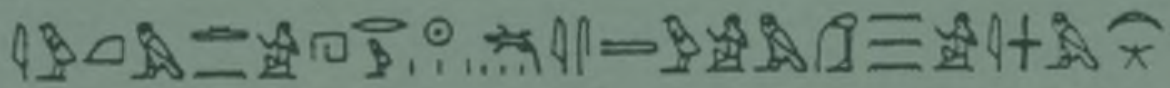

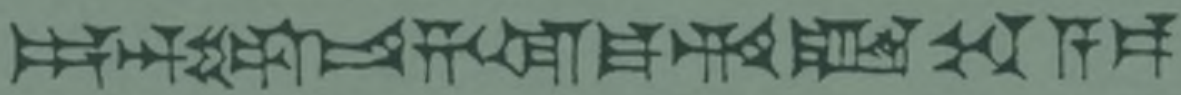

MHNIN AEI $\Delta \mathrm{E} \Theta \mathrm{EA}$ ПH$\Lambda \mathrm{HIA} \triangle \mathrm{E} \Omega$ 


\title{
FORAM OS HITITAS HENOTEÍSTAS? A PALAVRA ŠIU NO CONTEXTO DO HITITA DO ANTIGO REINO
}

\author{
ANTÓNIO JOSÉ GONÇALVES DE FREITAS \\ Universidade do Minho \\ antonio.defreitas@googlemail.com
}

\section{Resumo}

Este trabalho tem como objectivo analisar o contexto, o referente e o objecto associado à palavra hitita Šiu, cujo significado primordial faz etimologicamente referência à palavra do proto-indo-europeu *dyeu. Apresento o ponto da situação e ofereço um esboço duma solução alternativa aos problemas que derivam da leitura desta antiquíssima palavra hitita, ao mostrar eventuais indícios de um possível henoteísmo no período do hitita antigo.

\begin{abstract}
This paper aims to analyze the context, the referent and the object associated with the word Hittite Šiu, whose primary meaning is etymologically ${ }^{*} d y e u$, making reference to the Proto-Indo-European. I analyze the state of the matter and I provide an outline of an alternative solution to the problems that rise from the reading of that ancient Hittite word. That alternative solution seems to be consistent with the hypothesis of a henotheism.
\end{abstract}

O texto conhecido como Proclamação de Anitta', é um dos mais antigos documentos escrito na língua hitita. $O$ texto relata a gesta de Anitta, filho de Pithana, rei de Kanes, na sua conquista de Hatusa, a fundação do reino e a sua proclamação como rei de Hatti. É o primeiro 
documento histórico hitita, do qual preservamos uma cópia da época do Antigo Reino e outras cópias posteriores.

Do ponto de vista linguístico, o texto apresenta particularidades da língua hitita antiga, tais como a presença do ergativo, o uso do caso absoluto ou caso zero ${ }^{2}$ e do directivo. Entre essas particularidades aparece também a palavra ${ }^{d} S-i-u s-m i-i S^{3}$ e ${ }^{d} S-i-u s-s u$-mi-is que não é encontrada em nenhum outro texto conhecido até agora. Esta palavra é composta pela palavra ${ }^{d} S-i-u$ e a forma enclítica do possessivo da primeira pessoa do plural, -smi-is, e acompanhada também pela forma enclítica do possessivo da terceira pessoa do plural -su-mi-is, no caso nominativo. A outra particularidade é aparecer precedida pelo determinativo sumério DINGIR $\left({ }^{\text {d }}\right.$ ) que corresponde ao acádico Ilum, que em geral mostra a característica divina do nome ou coisa ao qual está aposto. Uma particularidade que junto com as características arcaicas da língua hitita mostra a sua antiguidade é o uso no começo do documento da palavra qibima, imperativo da segunda pessoa do singular do verbo acádico qabu.

A palavra Šiu é de origem indo-europeia, claramente derivada do proto-indo-europeu * dyeu e seu significado é deus, pertencendo ao género comum. A sua origem comum com o grego Zعúç é aceite sem nenhuma hesitação. ${ }^{4}$ No Hittite Inherated Lexikon ${ }^{5}$, ao comparar a sua etimologia com outras línguas anatólicas, mostra-se a sua pertença clara a um ramo da dialectologia anatólica na qual se incluem o palaico. Em palaico a palavra para deus é tiuna- (género comum) sendo seu nominativo singular ti-ú-na-as. Ao mesmo ramo dialectal pertence o lídio, onde a palavra equivalente, também do género comum, é ciw-, atestada no nominativo singular ciws, no acusativo singular ciwv e no dativo-locativo plural ciwav. Todas têm a sua origem no proto-indo-europeu * dyeu.

Portanto, não há problema em reconhecer o significado de Šiu, e temos evidências suficientes para sabermos que significa deus. Sim, temos outros problemas, consequências do contexto. Os problemas são: A que deus está-se a fazer referência? Refere-se a um deus em particular o ao conceito de deus? Caso não faça referência a um deus em particular, é o genérico para qualquer deus? As duas alternativas presentes nas perguntas propostas são aquelas discutidas na literatura e recolhidas no artigo de A. Gilan ${ }^{6}$ sobre Šiu em Reallexikon der Assyriologie und Vorderasischen Archäologie. Antes de continuar a discussão, transcrevo as linhas relevantes do texto Proclamação de Anitta $^{7}$, baseando a sua transliteração na edição de $\mathrm{Neu}$, sendo a tradução portuguesa minha. 
38. ut-ne-e hu-u-ma-àn-da URU Za-àl-pu-az an-da a-ru-na- àz [ Todos os países de Zalpuwa, no mar...

39. ka-ru-ú mU-uh-na-aš LUGAL URU Za-a-àl-pu-wa D ši-u-m šum [i-in]

Ubna tempos atrás, rei de Zalpuwa teve (a estátua) do nosso dSiu

40. [ $\mathrm{UR}_{\mathrm{R}} \mathrm{U}_{\mathrm{Ne} \text {-es-ša-az }} \mathrm{URU}_{\mathrm{Za} \text {-a-al-pu-wa pé-e-d [a-as] }}$ sequestrado em Nesa a (levou-a) Zalpuwa,

41. [ap-pé-]ez-zi-ya-na ${ }^{m} A$-ni-it-ta-aš LUGAL.GAL D Ši-ú-su [ $m$ $(m i-i n)]$

[...] ... mas eu Anitta, Grande Rei, trouxe, (a estátua) do nosso dSiu

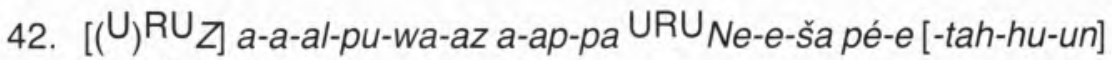
de [Z]alpuwa regresso a Nesa.

43. [m $\mathrm{m} u]-u z-z i-y a-n a$ LUGAL URU Za-a-al-p [u-wa] hu-š [u-wa-an-ta-an] todavia Huzziya rei de Zalpuwa, eu trouxe-a [...]

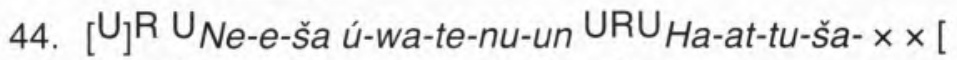
para Nesa. A cidade de Hattusa [

45. [ta]k?-ki-iš-ta ša-an ta-a-la-ah-hu-un ma-a-na-aš [] [...] ... [...]. Eu obtive-a. Quando eles (a cidade)

46. ap-pé-ez-zi-ya-na ki-iš-ta-an-zi-at-ta ša-an D Hal-ma-š [u-it-ti] mas a seguir ficaram famintos, eles deram ao meu dSiu

47. DŠi-i-uš-mi-iš pa-ra-a pa-iš ša-an iš-pa-an-di o trono da deusa Halmašuit, e à noite

48. na-ak-ki-it da-a-ah-hu-un pé-e-di-iš-ši-ma ZÀ.AH.LI-an a-ni$e-[$ nu-un ]

tomei-a pela força, e em seu lugar semeei erva daninha

49. ku-iš am-me-el a-ap-pa-an LUGAL-us ki-i-ša-r[i] Aquele que seja rei de Hattusa depois de mim

50. nu URU Ha-at-tu-ša-an a-ap-pa a-ša-a-š [i] e volte a repovoá-la, 
51. na-an ne-pí-ša-aš DISKUR-aš ha-az-zi-e-e[t-tu] que o deus da tormenta o esmague!

52. URU Ša-la-ti-wa-ra me-e-ni-i=m-me-et ne-e-eh-e-[hu-un] Voltei a minha cara para a cidade de Šalatiuwara.

53. URUŠa-la-ti-wa-ra me-e-na-ah-ha-an-da GIŠ A cidade, no entanto, movimentou sua tropas fora dela (de Šalatiwara)

54. [URU-ri-a] $z$ ÉRINMEŠ - ŠU hu-et-ti-ya-ti ša-an URU Ne-e-š [ (a pe-e-hu-t) e-nu-un]

Vim e levei-os para Nesa.

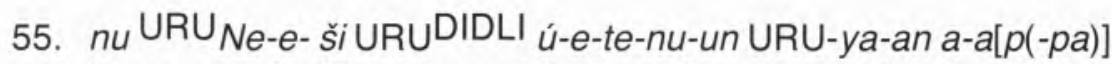
Nesa e eu fortificamos a cidade. Após a anexação da cidade

56. ne-pí-ša-aš DIšKUR-na-aš É-ir Ù É D Ši-u [-na-su (m-mi-i-n $A B-N I)]$

Construí um templo para o deus da tormenta dos céus e um templo para o nosso dSiu.

57. É D Hal-ma-šu-it-ta-aš É DIŠKUR-na-aš [(BE-LI-YA Ù É D Ši-una-sum-mi-iš $A B-N I)]$

Um templo para Halmašuit, um templo para o deus da tormenta, meu senhor, e um templo para o nosso dSiu construí.

58. KASKAL-za ku-it a-aš-šu ú-tah-h [u-un (a-pe-e-da-an-da ha-liš-ši-ya-nu-un)]

Como é sabido, a língua hitita, seguindo a tradição acádica, utiliza o determinativo sumério DINGIR $^{8}$ antes dos nomes dos deuses ou dos objectos deificados para indicar o seu carácter divino. Isto levanta um problema: se a palavra Šiu significa deus, porque apôs-se a esta o determinativo DINGIR? A resposta mais imediata para isto é que Šiu é o nome de um deus, como no caso do grego Zeus, e portanto pede o uso do determinativo. Mas, o hipotético deus Šiu não é parte do panteão hitita, pelo menos não temos notícia nesse sentido, já que para além do texto de Anitta a palavra Šiu não é usada mais. Portanto, é possível que a palavra faça referência a outra divindade. Tal como Gillan ${ }^{9}$ afirma, Hrozny e outros investigadores, no inicio da hititologia, consideraram que Šiu era o nome de um deus em particular. Se assim fosse, o passo a seguir é 
determinar de qual deus ou objecto deificado estamos a falar; mas isso não é simples, porque num caso a palavra em questão é d Siusumi (nosso Šiu) e a outra é dSiusmi (o Šiu deles), multiplicando o problema.

Para dar solução a esse problema, nos anos 70 de século passado, $\mathrm{Neu}^{10}$ na sua edição da Proclamação de Anitta identifica Šiu com o deus solar, grafado como dUTU. O seu argumento baseia-se em que a palavra Šiu manteve a ligação ao significado original indo-europeu * dyeu, que representa o deus da luz do céu ou a luz do céu deificada ${ }^{11}$, que será logo substituída pela forma hatiana do deus solar, Estan, e posteriormente "hititizado" como Istanu*. A interpretação de Neu foi secundada por Carruba ${ }^{12}$ e Tischler ${ }^{13}$. Posteriormente Starke ${ }^{14}$, identificou Šiu com a deificação do trono, Halmasuit*. A seguir à proposta de Starke, Singer ${ }^{15}$ propôs o que podemos dizer, uma solução salomónica. Para Singer, a referência a Šiu como nosso deus, ${ }^{d}$ Siusummin, aparece associado à estatua que foi trazida de volta a Nesa, por Anitta desde Zalpuwa ${ }^{16}$, lugar para onde tinha sido levada por Uhna. Para isso Singer, na linha 46, em lugar da reconstrução de Halmasuit* como ${ }^{\mathrm{d}} \mathrm{Hal}-\mathrm{ma}-\mathrm{s}^{\star}[u-i t-t]$, que corresponde ao dativo, colocando o trono deificado como objecto indirecto da oração, prefere a reconstrucção $\mathrm{Hal}-m a-s[u-i-i z]$, o que colocaria Halmasuit* como sujeito da oração, e nesse caso devíamos ler: "Mas, quando isto (Hattusa) [...] subsequentemente teve a praga da fome, Halmasuit, "o deus deles", rendeu-a ( $\mathrm{a}$ mim) e tomei-a à noite, tempestivamente". O problema que eu encontro nesta reconstrução é que parece apontar para que Šiu fosse um deus venerado por Anitta. Mas sabemos que Anitta e Pithana, seu pai, são nomes não indo-europeus. Como explicar que um rei invasor não indo-europeu tivesse a preocupação de recuperar a estátua de um deus indo-europeu para estabelecer-se numa cidade não indo-europeia e chamar a este deus "nosso deus". Essa consequência apresenta-se-me mais complexa de explicar do que supor que Šiu era deus dos hatianos, razão pela qual Anitta trouxe de volta a sua estatua e declarou-se seu venerador ao chamá-lo «nosso deus». E assim com essa afirmação, Anitta justificava a sua «realeza», como se por acção de Šiu tivesse direito a sentar-se no trono sagrado.

Finalmente, seguindo a Singer, Kryszat ${ }^{17}$ sugere que ${ }^{d}$ Siusummin deve ser identificado com Anna, deidade principal de Kanes (Nesa). $O$ problema que se enfrenta aqui é que essa deidade hatiana tem sido escassamente documentada, e ainda que propõem uma outra hipótese, em lugar de esclarecer, complica mais o assunto. 
Finalmente, sem querer oferecer uma análise completamente diferente do problema sobre a semântica de dSiu, tenho sim várias perguntas que se dirigem para uma outra possível explicação.

Em primeiro lugar, ter-se-ia de explicar o porque do uso do determinativo sumério aposto à palavra hitita Šiu, tendo em consideração que não há dúvidas sobre a derivação etimológica de Šiu, o seu significado é deus, i.e., porque adicionar o determinativo de deidade a uma palavra que significa deus? Uma explicação seria o aceitar que a palavra em questão perdeu o seu significado ou que este foi esquecido, e que esta palavra passou a significar o nome de um deus particular. Também pode indicar que o deus Šiu fosse um deus único ou principal, o que concordaria com a hipótese de Kryszat esboçada anteriormente. Isto pode indicar que 'o nosso deus' e 'o deus deles' fizesse referencia a um único deus venerado pelos hatianos. Assim Anitta, após ter conquistado Hatti, reconhece este deus Šiu como seu, para poder legitimar o seu poder real, o que viria ao encontro da proposta de Kryszat. Aceitando essa proposta, podemos dar-Ihe maior consistência, se juntar-mos a hipótese de Lord Renfrew, para quem o berço do povo indo-europeu é na Anatólia ${ }^{18}$. Com essa hipótese adicional explicar-se-ia a antiguidade da própria palavra, associada ao mesmo conceito de deidade, mas que com o tempo pensou-se como o nome de um deus que por ser o principal não teria nome. A partir dai, parece surgir naturalmente a hipótese de um possível henoteísmo ${ }^{19}$, o qual seria prévio ao politeísmo que caracterizará o povo hitita. É claro que para poder aceitar estas hipóteses e responder a outras questões de forma adequada, faz-se necessário uma análise do problema religioso da Anatólia do segundo milénio, de forma mais extensiva do que aquela feita por Piotr Taracha ${ }^{20}$. Ao mesmo tempo, seria conveniente desenvolver uma análise particular para tentar esclarecer de forma mais aguda o que caracteriza os deuses para os hititas, tentando em última análise responder à questão "O que é um deus?" para os hititas. Este tipo de análise tem sido feito de forma mais genérica no caso da Mesopotâmia, como por exemplo no livro editado por Porter ${ }^{21}$. Analogamente e com ajuda do material desenvolvido nele, teremos de fazer uma análise semelhante no caso hitita, com a dificuldade que implica o estudo do período mais antigo da língua e civilização hititas.

Responder a esses e a outros problemas apresentados neste estudo são os meus objectivos de investigação a desenvolver em futuros trabalhos*. 


\section{Notas}

(1) Corresponde a CTH 1, editado em NEU, Der Anitta Text e em Carruba, Anittae res gestae.

(2) PATRI, L'alignement syntaxique, 90.

(3) Atestada em KBo III 22 rev. 47, e correspondente a um nominativo singular. Para detalhes veja-se GESSEL, Onomasticon, p. 407.

(4) CHANTRAINE, Dictionnaire Étymologique, p. 399.

(5) KLOEKHORST, Hittite Inherated Lexicon, pp. 880-881.

(6) GILAN, "Siu», in Reallexikon der Assyriology, pp. 559-560.

(7) Transliteração de KBo III 22 baseada na edição de Neu, Der Anitta text.

(8) O uso do determinativo sumério DINGIR é complicado. É usado colocado em frente do nome de deuses, mas também pode ser colocado junto a nome de objectos deificados, objectos que tenham sido usado por deuses ou partes da natureza consideradas como divinas (rios, montanhas, árvores, etc). Uma interessante discusão tratando de precisar o uso de DINGIR é feita, em forma de entrevista, em PORTER, What is a God?, 204-6.

(9) GILLAN, 'Siu' in Reallexikon der Assyriologie, p. 559.

(10) NEU, o.c., 116-131.

(11) KLOEKHORST, Hittite Inherited Lexickon, 763-766.

(12) CARRUBA, o.c., 37.

(13) TISCHLER, Hethitisches etymologisches Glossar, 1074-1079

(14) STARKE, Halmasuit im Anitta text, 47-65

(15) SINGER, “"Our god" and "their god" ", 343-349

(16) Ver linhas 39-40 da transliteração do texto.neste artigo.

(17) KRYSZAT, «Herrscher, Kult und Kulttradition...", 206.

(18) RENFREW, Archaeology \& Language, the puzzle of Indo-European Origins, London, 1987, pp. 75-98, onde ele dicute o problema do lugar de origem dos indo-europeus.

(19) Henoteísmo é por definição o crença num deus considerado, não como único, mas como o mais relevante, e algumas vezes o único merecedor de receber culto.

(20) TARACHA, Religions of second millennium Anatolia, pp. 36-79.

(21) PORTER, What is a god?

Agradeço à FCT que financiou a minha estadia na Alemanha no Lehrstuhl für Altorientalistik, Universität Würzburg, com verbas da bolsa SFRH/BPD/70292/2010. Agradeço também aos colegas do Lehrstuhl für Altorientalistik, Universität Würzburg e de forma especial a seu director, Prof. Dr. Daniel Schwemer, pelo apoio oferecido durante a minha estadia, na qual desenvolvi a investigação que parcialmente é apresentada neste artigo. 


\section{Bibliografia:}

Onofrio CARRUBA, Anittae res gestae (= StMed. 13), Pavia, 2003.

Pierre CHANTRAINE, Dictionnaire Étymologique de la langue Grecque. Histoire de Mots, tome II, Paris, 1970.

Ben H. L. van GESSEL, Onomasticon of the Hittite Pantheon. Part One, Leiden, 1998.

A. GILAN, "Siu», in Reallexikon der Assyriologie und Vorderasischen Archäologie, Berlin, 2011.

Alwin KLOEKHORST (ed.), Etymological Dictionary of the Hittite Inherited Lexicon (Indo-European etymological dictionary 5), Leiden, 2008.

G. KRYSZAT, "Herrscher, Kult und Kulttradition in Anatolien nach den Quellen aus den altassyrischen Handelskolonien - Teil 3/2: Grundlagen für eine neue Rekonstruktion der Geschichte Anatoliens und der assyrischen Handelskolonien in spätaltassyrischer, Zeit II", Altorientalische Forschungen (Schriften zur Geschichte und Kultur des Alten Orients), 35 (2008), 195-219.

NEU, Erick, Der Anitta Text (= StBoT 18) (Wiesbaden, 1974).

Barbara Nevling PORTER (ed.), What is a god? Anthropomorphic and non-Anthropomorphic Aspects of Deity in Ancient Mesopotamia, Winona Lake, 2009.

Silvain PATRI, L'Alignement syntaxique dans les langues indo-européennes d'Anatolie, (=StBoT 49), Wiesbaden, 2007.

Colin RENFREW, Archaeology \& Language, the puzzle of Indo-European Origins, London, 1987.

Itamar SINGER, "Our god" and "their god" in the Anitta Text", in O. Carruba, M. Giorgieri and C. Mora (ed.), Atti del I/ congresso internazionale di Hittitologia (= StMed. 9), Pavia, 1995.

Oğuz SOYSAL, «Philological Contributions to Hattian-Hittite Religion (I)», in Journal of Ancient Near Eastern Religions, 8, 1, 2008, pp. 45-66.

Frank STARKE, «Halmasuit im Anitta-Text und die hethitische Ideologie vom Königtum», Zeitschrift für Assyriologie und Vorderasiatische Archäologie, 69, 1979, 47-65.

Piotr TARACHA, Religions of second millennium Anatolia, Wiesbaden, 2009.

J. TISCHLER, Hethitisches etymologisches Glossar, S/2, 2006, 1073-1087. 